\title{
Crise estrutural, crise urbana e militarização do território: uma análise sobre o urbanismo miliciano-militar no Rio de Janeiro
}

Strutural crisis, urban crisis and territory militarization: an analysis on militian-military urbanism in Rio de Janeiro

Crise structurelle, crise urbaine et militarisation du territoire: une analyse sur l'urbanisme milicien-militaire à Rio de Janeiro

Crisis estructural, crisis urbana y militarización del territorio: un análisis del urbanismo miliciano-militar en Rio de Janeiro

\section{Utanaan Reis Barbosa Filho}

\section{(2) OpenEdition}

\section{Journals}

\section{Edição electrónica}

URL: https://journals.openedition.org/espacoeconomia/21097

DOI: 10.4000/espacoeconomia.21097

ISSN: 2317-7837

\section{Editora}

Núcleo de Pesquisa Espaço \& Economia

Refêrencia eletrónica

Utanaan Reis Barbosa Filho, «Crise estrutural, crise urbana e militarização do território: uma análise sobre o urbanismo miliciano-militar no Rio de Janeiro», Espaço e Economia [Online], 22 | 2021, posto online no dia 15 janeiro 2022, consultado o 13 agosto 2022. URL: http://journals.openedition.org/ espacoeconomia/21097; DOI: https://doi.org/10.4000/espacoeconomia.21097

Este documento foi criado de forma automática no dia 13 agosto 2022.

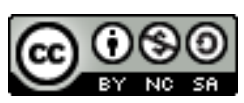

Creative Commons - Atribuição-NãoComercial-Compartilhalgual 4.0 Internacional - CC BY-NC-SA 4.0 https://creativecommons.org/licenses/by-nc-sa/4.0/ 


\section{Crise estrutural, crise urbana e militarização do território: uma análise sobre o urbanismo miliciano-militar no Rio de Janeiro}

Strutural crisis, urban crisis and territory militarization: an analysis on militian-military urbanism in Rio de Janeiro

Crise structurelle, crise urbaine et militarisation du territoire: une analyse sur l'urbanisme milicien-militaire à Rio de Janeiro

Crisis estructural, crisis urbana y militarización del territorio: un análisis del urbanismo miliciano-militar en Rio de Janeiro

Utanaan Reis Barbosa Filho

\section{Introdução}

1 A violência no Rio de Janeiro tomou proporções agudas no século XXI, o que motivou esforços de pesquisa nas mais diversas áreas do conhecimento, trazendo, obviamente, cada qual a sua maneira, um olhar específico sobre a realidade. Dentre os estudos realizados, as milícias concentram, hoje, o maior esforço de compreensão e acompanhamento - seja de acadêmicos ou de órgãos do poder público -, dado a expansão, cartilha de serviços e lucratividade.

2 Apesar de estudos consagrados sobre a articulação de grupos de extermínio na Baixada Fluminense desde a década de 1960, como é o caso dos trabalhos do sociólogo José Cláudio Souza Alves (ALVES, 2008; 2019 [2003]) e a formação das milícias na Zona Oeste (BURGOS, 2002), a tomada de consciência do problema das milícias - entendendo-as como um processo complexo e com ramificações nas esferas públicas - é recente. Datase que a repercussão das milícias no Rio de Janeiro enquanto fenômeno e como um novo problema social se deu a partir de $2008^{1}$, com a CPI das Milícias instaurada pela 
Assembleia Legislativa. A partir disso, definiram-se as principais características das milícias: domínio territorial; coação de moradores e comerciantes para exploração econômica (cobrança direta e venda de serviços, terrenos ou objetos essenciais); legitimação social através do discurso de combate ao tráfico de drogas e a "bandidagem"; participação de agentes estatais armados; e ocupação de cargos e legislaturas políticas. Ou seja, existe uma estrutura forte de atuação política e econômica amparada no uso de armas de fogo.

3 As pesquisas que se concentram no estudo das milícias no Rio de janeiro usualmente buscam caracterizar suas formas de atuação exploratória, montam uma cartografia da violência, mensuram impactos econômicos de sua articulação, analisam as estratégias de capilaridade e formação de consenso. No entanto, apesar da relevância e contribuição desses estudos, nota-se certa escassez em averiguar tal fenômeno como parte de um fenômeno maior, de tendência mundial, que encontrou terreno fértil no Rio de Janeiro. Isso faz sentido com o avanço notório que as milícias empreenderam nos últimos quinze anos sem que houvesse qualquer ação efetiva por parte do poder público, além do momento em que a cidade do Rio de Janeiro vivenciava: readequação enquanto cidade global, atraindo investimentos, especialmente por meio de eventos como os jogos Pan Americanos (2007), Jogos Mundiais Militares (2011), Olimpíadas e Paraolimpíadas (2016), Jornada Mundial da Juventude (2013) e Conferência Rio +20 (2012), no qual ensejou-se uma irrestrita militarização do território. Pois, "se o modelo de cidade buscado no neoliberalismo tem como uma de suas facetas a gestão urbana nos moldes de uma empresa, o outro lado da moeda é o urbanismo militar, a extensão das ideias e técnicas militares para o cotidiano das cidades" (VALENTE, 2017, p.17).

Destarte, a partir do estudo das milícias, em especial suas formas de atuação (política, econômica e social) na cidade do Rio de Janeiro, visa-se lograr aportes para corroborar a hipótese de que as milícias no século XXI se inserem num processo de reorganização das cidades neoliberais - as ditas cidades globais/empresariais - e no processo de militarização do território, os quais são fenômenos que se entrelaçam.

5 Para tanto, na primeira seção "crise e seu caráter estrutural" visa-se fazer um panorama dos antecedentes da crise dos anos 1970 e os fundamentos que nos permitem atribuir o nome de crise estrutural do capital, que se arrasta até a atualidade, imprimindo fisionomias e tentativas de revigorar o capitalismo. Já na seção "crise urbana, cidades neoliberais e militarização do território" busca-se analisar a crise urbana brasileira como uma face da crise estrutural - obviamente fazendo mediações com as características da conformação das cidades brasileiras - e os impactos com a chegada do neoliberalismo e a reorientação da cidade do Rio de Janeiro enquanto cidade global/empresarial, onde se intensificam as características da militarização do território - ou do novo urbanismo militar - que, apesar de tendência mundial, acha cenário privilegiado no Rio de Janeiro de forma a realçar os conflitos de baixo impacto e intensidade do cotidiano, os enclaves fortificados e à tendência a securitização em todas as esferas da vida social. Por fim, na seção "as milícias no Rio de Janeiro", resgatase o surgimento dos grupos de extermínio, sua atuação e complexificação ao longo do tempo, bem como sua articulação no poder público inclusive ocupando cadeiras no legislativo e executivo, além de seu processo de enriquecimento com uma cartilha ampla de serviços e seu domínio do território.

6 Espera-se que a análise do processo de militarização do território e do urbanismo miliciano a partir da interpretação que este faz parte da crise urbana e que esta crise é 
uma face da crise estrutural do capital, possa contribuir para o entendimento das cidades frente às milícias e o porquê da expansão desses grupos "paramilitares".

\section{Crise e seu caráter estrutural}

7 Em 1944, após a crise de 1929 e ainda com a Segunda Guerra Mundial em vigor, diversos países se reuniram em Bretton Woods com a finalidade de reconstruir e reestruturar o capitalismo mundial e, principalmente, o sistema financeiro internacional, de modo que fosse possível promover a estabilidade econômica no pós-guerra. Para tanto, um conjunto de regras foi criado para regular a política econômica internacional: a definição de paridades cambiais ajustáveis sob supervisão do FMI, isto é, as moedas estariam congeladas ao valor do dólar com uma pequena margem de manobra para mais e para menos. Assim como a moeda norte-americana, por sua vez, estaria ligada ao valor do ouro.

Para dar suporte ao novo sistema internacional e garantir liquidez na economia, foram criadas instituições multilaterais como o Fundo Monetário Internacional (FMI) e o Banco Mundial. No limite, o que se colocava para os países era maior primazia para os fluxos, relativamente, livres de comércio e capitais, "sem obstáculos, do comércio entre as nações, dentro de regras monetárias que garantissem a confiança na moeda-reserva, o ajustamento não deflacionário do balanço de pagamentos e o abastecimento da liquidez" (BELLUZZO, 1995, p. 12).

Paralelamente à regência do acordo de Bretton Woods, houve a conformação dos Estados de bem-estar social nos países capitalistas centrais. Segundo Oliveira (1988) estes Estados, teorizados pelos ditames keynesianos, instituíram um novo padrão de financiamento público de forma abrangente, ou seja, ao mesmo tempo em que atenderia as demandas do capital, faria o "mesmo" pela classe trabalhadora: "o fundo público em suas diversas formas, passou a ser o pressuposto do financiamento da acumulação de capital, de um lado, e, de outro, do financiamento da reprodução da força de trabalho" (OLIVEIRA, 1988, p. 8). As tendências de crise por um lado e as crescentes manifestações do operariado por outro, pressionaram o Estado a dar as respostas aos interesses do capital, mas sem, no entanto, deixar de lado as reivindicações da classe trabalhadora. Como exemplo dos financiamentos via políticas públicas para a classe trabalhadora e sobre as formas de acumulação de capital:

A medicina socializada, a educação universal gratuita e obrigatória, a previdência social, o seguro-desemprego, os subsídios para transporte, os benefícios familiares (quotas para auxilio-habitação, salário família) e, no extremo desse espectro, subsídios para o lazer, favorecendo desde as classes médias até o assalariado de nível mais baixo, são seus exemplos. A descrição das diversas formas de financiamento para a acumulação de capital seria muito mais longa: inclui desde recursos para ciência e tecnologia, passa pelos diversos subsídios para a produção, sustentando a competitividade das exportações, vai através dos juros subsidiados para setores de ponta, toma muitos países a forma de vastos e poderosos setores estatais produtivos, cristaliza-se numa ampla militarização (as indústrias e os gastos em armamentos), sustenta a agricultura (OLIVEIRA, 1988, p. 8).

Apesar do Estado nos países ocidentais ter se colocado como mediador da luta de classes e muitas vezes ser enxergado - de forma míope - como um ente extremamente comprometido com a aplicação da legislação social, como um Robin Hood que tira do capital para dar ao trabalho, as políticas keynesianas e a criação do Welfare State nos países da Europa Ocidental tinham a finalidade estratégica de promover o crescimento 
econômico, amenizar e conciliar o embate de classes e, principalmente, promover a reprodução do modo de produção capitalista. Para tanto, a alternativa encontrada foi estabelecer além do crescimento na esfera da produção, sua realização na esfera da circulação, isto é, aumentar a necessidade de consumo; possibilitar tempo - lazer - para as pessoas consumirem.

11 Segundo Pochmann (2004), as três décadas que sucedem o final da Segunda Guerra mundial (1945-1973) são compreendidas como período de maior glória do capitalismo, pois neste período os países do capitalismo central vivenciaram, além dos ganhos sociais, estabilidade econômica: crescimento com baixo desemprego, aumento da capacidade industrial estimulado fundamentalmente por investimentos públicos, elevação do padrão de vida da população, etc. Estes fatores consagram tal período como os "anos de ouro do capitalismo".

12 Por outro lado, as nações que compõem a periferia do capitalismo não vivenciaram os avanços na proteção social e trabalhista como o centro. Pode-se dizer, tomando o Brasil como exemplo, que houve crescimento econômico pujante, entretanto, não ocorreu diminuição considerável da desigualdade social, da pobreza, expansão da legislação trabalhista, etc. Ou seja, não ocorreu a combinação de estabilidade e crescimento econômico com ampliação de direitos, como na experiência de países ocidentais (POCHMANN, 2004). Além disso, o crescimento via industrialização ocorreu mediante a instalação de empresas estrangeiras monopolistas na periferia do capitalismo, onde encontravam possibilidade de instalar o capital excedente, e dessa forma aumentar a extração de mais-valor, haja visto os mecanismos de superexploração da força de trabalho, abundância de matérias primas e parca legislação trabalhista.

O sucesso do Estado de bem-estar social, sustentado durante quase trinta anos entra na década de 1970 apresentando fortes limites e obstáculos para sua manutenção. Muitos argumentos e hipóteses são elencadas sobre este período, o que torna sua análise ampla, complexa e dispare dependendo da lupa utilizada. No entanto, alguns fatos relevantes permitem a compreensão do momento: primeiro, durante os vinte anos subsequentes da Segunda Guerra Mundial, os Estados Unidos reforçaram sua hegemonia monetária e financeira, sendo financiador da reconstrução da Europa e do Japão, bem como, em menor medida, dos processos de industrialização da América Latina, fato este que possibilitou ganhos substanciais à economia estadunidense. A recuperação destes países e a expansão do mercado mundial abriu espaço para que outras nações iniciassem uma disputa econômica, tecnológica e organizacional, e reduzissem a dominação econômica dos Estados Unidos de forma a colocar em xeque o poder de ouro do dólar (BELLUZZO, 1995; BRENNER, 2013). Acrescenta-se, ainda por estes motivos, os recorrentes déficits no balanço de pagamentos dos EUA. Desse modo, a perda de supremacia dos Estado Unidos e as pressões de oferta de dólar que causavam déficits comerciais fizeram com que em 1971 o presidente Richard Nixon abandonasse a convertibilidade do dólar em ouro, procedendo, por conseguinte, uma grande desvalorização cambial seguida, imediatamente, pelo "restante" do mundo, entrando numa nova era de desvalorizações cambiais competitivas. Isto conferiu aos EUA uma evidente vantagem fiscal e promoveu uma grande elevação dos preços em dólares dos insumos industriais. A quebra de conversibilidade marca o fim do acordo de Bretton Woods.

14 A década de 1970 possuí muitos fatores "conjunturais" que auxiliam na explicação da crise e da reconfiguração do capitalismo: crise do petróleo, Guerra Fria, quebra da 
conversibilidade, etc. Entretanto, sob a ótica marxista - focando nas relações de produção e forças produtivas - a onda de crescimento começa a sinalizar que perdia força desde o final da década de 1960, entrando na década de 1970 com brusca desaceleração e redução das taxas de lucro, de maneira que durante esta década esgotase o modelo fordista-keynesiano que ditou os anos do pós-guerra (MÉSZÁROS, 2009; HARVEY, 2002 [1989]). De acordo com Harvey (2002 [1989]), os anos de 1970 representam uma crise de sobreacumulação que ocasionou estagnação do PIB, do salário real e da formação bruta de capital fixo, o que significou um baixo dinamismo do setor produtivo.

15 A questão essencial que se coloca é que seria impossível ao sistema capitalista manter o prolongamento do modelo keynesiano indefinidamente para sustentar seu processo de acumulação. Ora, o que o capitalismo vivenciava era o problema da auto-expansão da realização do valor sob a dinâmica de busca incansável pela absorção de excedentes e do conflito com a exigência de expansão da força de trabalho, ocasionando desemprego estrutural. E, como o caráter expansivo do capital se corroía, não havia mais alternativas, ou seja, era necessário "administrar a crise".

Sucintamente, uma crise econômica se instaura toda vez que o capital desenvolve e exacerba sua capacidade produtiva, levando assim à superprodução. Esta situação leva à destruição de mercadorias, meios de produção e, inclusive, força de trabalho (diminuição da oferta de trabalho). Após esse período ocorre uma reorganização da dinâmica capitalista de produção, no qual salários diminuem, ocorre migração de setores, os maiores produtores (monopolistas) engolem os menores, acentuando a concentração de capital e aumentando a capacidade produtiva, de modo que o ciclo recomeça até atingir um novo ápice e entrar em crise (TONET; LESSA, 2012).

Não obstante, como assevera Mészáros (2002), a crise que se instaura difere de todas as outras, inclusive da grande depressão de 1929, a qual o autor avalia como uma crise pujante, mas não universal e tampouco estrutural. Para o autor, o que muda a crise estrutural do capital das crises cíclicas anteriores é a manifestação de quatro aspectos:

[...] seu caráter é universal, em lugar de restrito a uma esfera particular [...] Seu alcance é verdadeiramente global [...] em lugar de limitado a um conjunto particular de países [...]. Sua escala de tempo é extensa, contínua, e, permanente, em lugar de limitada e cíclica, como foram todas as crises anteriores do capital; em contraste com as erupções e os colapsos mais espetaculares e dramáticos do passado, seu modo de se desdobrar poderia ser chamado de rastejante [...] (MÉSZÁROS, 2002, p. 796).

18 A nova forma de ser da crise excluí, segundo o autor, intervalos cíclicos entre recessão e expansão, sendo frequente e contínua. A "crise deixou de ser um fenômeno intermitente para se converter no modo permanente de reprodução da sociedade burguesa" e "todas as contradições sociais se intensificam em escala planetária" (TONET; LESSA, 2012, p. 73). Seguindo a mesma leitura de Mészáros, o filósofo brasileiro José Chasin ${ }^{2}$ explicita que

na crise atual do capitalismo hipermaduro, o desenho que se mostra, do tópico ao profundo, é a do colosso desgovernado/desgovernante. [...] os vasos comunicantes, pelos quais o sistema se repõe, co-exibem a simultaneidade de uma perturbação estrutural permanente e irreversível, a despeito dele conservar, ainda que essencialmente de forma manipulatória, a capacidade de recorrer a reciclagens periódicas, reduzidas, por certo, à condição de atos da pura gerência continuada de uma crise ininterrupta (CHASIN, 1983, p. 12). 
Outra questão relevante sublinhada por Mészáros $(2002 ; 2009)$ que sustenta o argumento da crise estrutural é a crise na realização do valor. 0 autor explicita que nesse período o sistema do capital não pode - e não consegue - se desenvolver sem recorrer à taxa de utilização decrescente do valor de uso das mercadorias, a saber, o capital não articula de forma separada, mas ao contrário, subordinando o primeiro (necessidades) ao segundo (valorização do valor). Isto posto, o argumento central que se coloca é que o valor de uso não necessariamente - e isso se apresenta como tendência - será utilizado, mas, diga-se, desde já, sem deixar de ter sua utilidade essencial para o capital: valorização do valor.

20 A partir dos elementos elencados acima, Mészáros (2002) afirma que a crise é estrutural, pois não é capaz de controlar sua lógica destrutiva e resolver as contradições da reprodução ampliada no interior da ordem capitalista. Ainda assim, atento à dinâmica concreta do modo de produção capitalista, entende que o "poder do capital, em suas várias formas de manifestação, embora longe de ter se esgotado, não consegue mais se expandir" (2002, p. 933). E Chasin arremata "viver e sobreviver para o capital tornou-se existir na e através da crise" (2000, p. 181). Ou seja, os autores concordam que existe uma crise estrutural, porém percebem que o capital apesar das dificuldades de elevar suas taxas de lucratividade, continuaria sua tônica de transpor seus próprios limites para se autoexpandir: "é claro que seria um tanto ingênuo sugerir que daqui para frente não haveria mais saída para a expansão capitalista e para o deslocamento manipulatório de muitos de seus problemas" (MÉSZÁROS, 2002, p. 1063). Desse modo, um conjunto de medidas foram tomadas nas décadas subsequentes na tentativa de reversão das decrescentes taxas de lucro.

21 Em resposta à crise empreende-se uma série de estratégias na perspectiva de retomar o crescimento e, sobretudo, de melhorar as taxas de lucro, agora sob a égide do capital financeiro. Os aspectos notórios dessa fase do capitalismo foram a mundialização do capital, a continuidade da hegemonia dos EUA, a financeirização da economia, a precarização do trabalho e sua irrestrita flexibilização, desemprego, elevação das dívidas públicas dos Estados e as enormes transformações tecnológicas (NETTO; BRAZ, 2008). Além da substituição do modelo fordista-keynesiano pelo toyotista e surgimento de uma nova fase do capitalismo, o neoliberalismo, enquanto ideologia política, social e econômica.

22 As medidas empreendidas não asseguraram um novo ciclo de expansão. Até pode ser razoável citar alguns países que cresceram consideravelmente, inobstante, este crescimento é pontual e individualizado, de forma a requerer explicações e análises específicas. Ademais, como pontua Botelho (2013), a forma encontrada para amenizar e administrar as crises se deu através de "fugas para frente", isto é, produção em abundância de liquidez e novas esferas especulativas capazes de criar a ilusão de que ocorre de fato o processo de valorização, visto que a principal manifestação das crises é de superacumulação, os mercados de capitais possibilitam simular um crescimento econômico. Ou ainda, através dos gigantescos e consagrados programas para reaquecer a economia, financiados pelos governos - fundamentalmente, via crédito - com a esperança de saída definitiva da crise.

23 Tais fenômenos econômicos e sociais expostos tiveram rebatimentos em todas as esferas da vida social: saúde, educação, mundo do trabalho, e muitas outras, sendo, inclusive, um caso emblemático a crise urbana e as respectivas alternativas encontradas através dela para uma suposta garantia de crescimento econômico. 


\section{Crise urbana, cidades neoliberais e militarização do território} ao longo dos séculos XVIII e XIX, os países de industrialização tardia, como o Brasil, vivenciaram este processo ao longo do século XX. O Brasil após a crise de 1929 iniciou o Processo de Substituição de Importações (PSI), de forma que, basicamente, durante os quarenta anos seguintes acumulasse altas taxas de crescimento. Isto trouxe consigo um rápido e desigual processo de urbanização, pois ocorreu intensa migração do campo para a cidade (principalmente nos locais que vivenciaram atividades econômicas durante o período colonial). Este processo garantiu às novas populações urbanas melhores condições de vida e acesso a determinados serviços, não obstante, no que tange à ocupação das cidades estas pessoas - em sua grande maioria com baixos salários - se fixaram nas periferias e favelas, construindo suas próprias moradias, em áreas ambientalmente frágeis ou em espaços ilegais, de forma desordenada, sem assistência técnica e vivendo as melhorias sociais através do clientelismo: troca de votos por pavimentação de ruas, por exemplo.

O processo tardio de industrialização contribuiu para uma grande segmentação social e política, e somado a isso, optou-se pela importação da matriz de planejamento urbano de base modernista/funcionalista com vistas a orientar o crescimento e desenvolvimento das cidades. 0 resultado disso foi uma modernização excludente e incompleta das cidades brasileiras, de maneira que a inclusão e regulação prometidas às camadas mais pobres, na prática, não ocorreram (MARICATO 2002). políticas universais: saúde, moradia, educação, previdência, planejamento urbano, etc.; na periferia do capitalismo (focando no caso brasileiro) isso não ocorreu ${ }^{3}$. Mesmo com bons índices de crescimento (principalmente, na década de 1970) o período é emblemático no tocante à compressão dos salários e a concentração de renda que, ainda assim, contribuiu para que a classe trabalhadora conseguisse se reproduzir socialmente de forma razoável.

Com a crise da década de 1970 e o esgotamento do Processo de Substituição de Importações, instaura-se nos países ocidentais diversas medidas para amenizar a crise; ao mesmo tempo estas medidas chegam a reboque na América Latina: reestruturação produtiva com a produção automatizada, horizontalizada e descentralizada territorialmente, baseada em tecnologias intensivas em capital e flexibilizadoras de força de trabalho; mundialização do capital e a liberalização/desregulamentação das finanças, ocorrendo uma reorientação da aplicação da riqueza que migra dos investimentos produtivos para as aplicações improdutivas (da economia real para a economia especulativa) (CHESNAIS, 2005); e o ajuste às teses liberais sob o jugo do neoliberalismo: forma organizativa da política e da economia.

Embora a constituição cidadã de 1988 tenha trazido avanços no que tange às formas de financiamento para as políticas sociais, ampliando a relevância do fundo público e do Estado na resolução dos conflitos sociais; construindo significativa legislação urbana, inclusive no que concerne à função social da propriedade; notória legislação ambiental e muitos outros temas sociais, a chegada do neoliberalismo no Brasil - mesmo que de forma tardia ${ }^{4}$ - trouxe consigo todas as concepções e fisionomias da lógica financeira e a perda do protagonismo do Estado. Nas palavras de Maricato:

Espaço e Economia, 22 | 2021 
Dominada pelo ideário neoliberal atinge uma realidade que não era plenamente moderna: conter investimentos em políticas sociais, privatização de serviços públicos; desregulamentação de algo que não era muito regulamentado; conter o investimento em serviço público num contexto que o serviço público não era universalizado; num contexto que a previdência não era universal. É muito diferente o neoliberalismo chegar na Inglaterra ou o neoliberalismo chegar no Brasil, é muito diferente! Então vivemos duas "décadas perdidas": 80 e 90. Num país desigual crescer $7 \%$ a.a. é muito diferente de um país desigual crescer a menos de um por cento ao ano, por isso chamamos aqui, essas décadas de perdidas. Isso teve um profundo impacto sobre a produção do ambiente construído (MARICATO, 2015, p. 15).

Ainda segundo Maricato (2013; 2015), o território foi totalmente modificado pelo neoliberalismo, no qual o campo se adequou à produção de commodities, expandindose e interiorizando a urbanização e aproximando cada vez mais o rural e o urbano, ou como definiu o geógrafo norte-americano Mike Davis, "em muitos casos, a população rural não precisa migrar para a cidade; a cidade migra até eles" (2006, p. 19). Nas cidades ocorreu a transformação de tudo em um grande negócio: privatização, desregulamentações, cidade empreendedora e competição entre as cidades. Como bem acentuou Lefebvre (2008), a nova tática do capitalismo procura, na verdade, ir além da compra e venda de parcelas do espaço urbano, pois visa reorganizar a produção subordinada às cidades. A cidade vira espaço funcional, prioritariamente destinado a acumulação e circulação de capital e detém estratégias de controle das massas. Ou seja, a cidade além de ser onde as pessoas vivem e ser um local de negócios, nela também há "um conjunto de capitais que tem interesses específicos na produção do espaço urbano" (MARICATO, 2015, p. 22), como o capital financeiro imobiliário ou o capital de construção e edificações, por exemplo.

30 A dinâmica de mercantilização, no contexto do neoliberalismo, imposta na década de 1990 e presente até hoje ${ }^{5}$ acentuou a crise urbana. Com a ampla abertura comercial e a redução do papel do Estado, ocorreu um brusco processo de desindustrialização e, em decorrência, aumento do desemprego, permanência da desigualdade social e uma brutal especulação imobiliária. Tais fatores consagraram a continuidade do processo de favelização, afastamento dos pobres dos centros mais ricos e dos centros dos empregos e aumento nos custos de vida e diminuição da qualidade de vida.

31 Ademais, com a consolidação do neoliberalismo um novo modelo de cidade é adotado no mundo: as ditas e exaltadas cidades globais. Este modelo foi implementado em cidades que desejavam se inserir em boas colocações internacionais para atrair investimentos, como é o caso do Rio de Janeiro desde a década de 1990, iniciada na gestão do prefeito César Maia ${ }^{6}$ com os recém chegados planejamentos estratégicos. Vainer (2002) sublinha que a inspiração desse planejamento é empresarial, tendo como nexo fulcral a problemática da competitividade urbana pelos melhores investimentos privados e recursos públicos extras, tecnologias, atração de novas indústrias e negócios, turistas e no preço e na qualidade dos serviços. Para os gestores ${ }^{7}$ urbanos, a cidade é como uma empresa que precisa de gestão eficiente, boa imagem e conhecida internacionalmente, ambiente de negócios e prospecção de investimentos, além de ser amigável ao mercado e orientado por e para o mercado. Nesse sentido, aprimorar a cidade à divisão espacial do consumo é fundamental: aeroportos, estádios, hotéis de luxo, festas e feiras, etc.

Gentrificação, inovação cultural, modernização física do ambiente urbano (inclusive o recurso aos estilos pós-modernistas de arquitetura e design urbano), atrações de 
consumo (estádios desportivos, shoppings e centros de convenção, marinas, restaurantes exóticos) e entretenimento (a organização de espetáculos urbanos temporários ou permanentes) se tornaram facetas muito mais proeminentes das estratégias para regeneração urbana. Acima de tudo, a cidade deve parecer um lugar inovador, excitante, criativo e seguro para viver ou visitar, onde se divertir e consumir (HARVEY, 1989, p. 9). tendência às novas formas de guerras do cotidiano, de baixo impacto e intensidade, diferente das grandes guerras mundiais de trincheiras entre Estados Nacionais. Por exemplo: "guerra civil molecular" (Hans Enzensberger), "guerra fria urbana" (Mike Davis, Edward Soja), "estado de exceção como paradigma de governo" (Giorgio Agamben) ${ }^{9}$. Todos visualizando a cidade como um local de resistência, luta, protestos e subversão, de forma que, para consagrar e manter o Estado neoliberal, deve-se buscar e arrojar os métodos de controle dos dissidentes e exclusão dos indesejados.

Apesar das cidades globais/empresariais e militarizadas serem um fenômeno mundial, no qual se incrementa "mais Estado" na área policial e nas prisões para solucionar o aumento generalizado da insegurança objetiva e subjetiva e "menos Estado" na área econômico-social (WACQUANT, 2007), este projeto é mais feroz na periferia, como é o caso do Brasil.

(...) a articulação da extrema desigualdade, da violência das ruas e da punição em massa nas cidades brasileiras sob o duplo consenso de Washington na economia de mercado e no controle do crime estimula a efetiva reductio ad absurdum do Estado a seu aparelho repressivo e à fusão de suas forças militares e civis para a manutenção 
da ordem. Isso transforma a segurança pública em um empreendimento marcial e o combate ao crime em um campo de prova para uma liderança política vigorosa voltada para os "resultados" imediatos e tangíveis. E faz com que a imposição da lei nos e ao redor dos infames bairros de classe baixa se transforme, literalmente, em uma guerra com seus moradores, com batalhas armadas e manobras, espionagem e execuções blindadas, controle de fronteiras e contagem de corpos, extensos "efeitos colaterais" e a vil demonização do "inimigo" pela mídia e as autoridades, incluindo o visível "repúdio a qualquer referência aos direitos dos criminosos" (WACQUANT, 2007, p. 215-216).

O Rio de Janeiro neste processo é emblemático, vide a polícia altamente militarizada e a segregação socioespacial.

A lógica de confinar determinados segmentos sociais, bem como manter a cidade do Rio de Janeiro vantajosa e turística ao mercado, fez com que a polícia intensificasse suas ações a fim de controlar/mascarar conflitos com os excluídos - e confiná-los ${ }^{10}$-, que há décadas vivem em condições precárias sem direito à cidade e, ademais, se propagasse as formas de securitização da vida (alguns exemplos nesse sentido são emblemáticos: UPPs, Guarda Presente e Segurança Presente, câmeras, Centros de Monitoramento, ocupação das favelas da Maré e do Complexo do Alemão pelo Exército Brasileiro, Incursões de Garantia da Lei e da Ordem (GLOs), aprovação da Lei Antiterrorismo, Intervenção Federal na segurança do Rio de Janeiro, etc.). Nesse processo, a milícia se consagrou como "aliada" do urbanismo militar, posto que o entendimento concreto desse grupo enquanto organização criminosa é recente.

Assim, as áreas marginalizadas vivenciaram diversos processos a fim de tornar a cidade bem quista, como é o caso das UPPs. No entanto, além da guerra às drogas, utilizada como mote para intervenções e ações nas favelas cariocas, outro fenômeno salta os olhos: a expansão e complexificação das milícias. Rocha e Motta (2020) tratando da relação entre megaeventos, militarização e milícias e a relação com a Zona Oeste do Rio de Janeiro, pontuam que a cidade foi dividida nesse processo entre "Luz e sombra", ou seja, uma parte esteve à frente dos holofotes, enquanto a outra parte foi colocada à sombra, posto que não possuí os signos da modernidade urbana - quanto mais apagada melhor. As milícias cresceram à sombra.

\section{As milícias no Rio de Janeiro}

Dentro da crise urbana as milícias foram vistas como um mal menor que poderia contribuir com o projeto de cerceamento e apaziguamento dos conflitos, de forma que sua capilaridade pelo território ocorreu a passos largos sem nenhuma forma de repressão. Por outro lado, a milícia cumpriu o papel que o Estado se ausentou, ou melhor, ocupou os vazios de poder deixados pelo Estado, a saber, segurança, prestação de serviços, como transporte entre outros; e impediu diversas formas de fiscalização.

De acordo com Alves (2008), Zaluar e Conceição (2007), as décadas de 1960, 1970 e 1980 assistiram à emergência de grupos de extermínio na Baixada Fluminense e Zona Oeste do Rio de janeiro. Em sua atuação inicial poucos funcionários do Estado se articulavam nestes grupos, porém, tão logo, ocorreu transmutações, de forma que ao longo das décadas descritas os grupos eram formados, fundamentalmente, por policiais militares, policiais civis, bombeiros e agentes penitenciários. Estes grupos atuavam com a prática de execução sumária, oferecendo proteção a comerciantes, defendendo a população de usuários de drogas e ladrões e investiam nos negócios imobiliários. Acrescenta-se ainda 
o apoio - seja com execuções, intimidações ou apoio local - a candidatos que pleiteavam cadeiras no legislativo ou executivo. Deve-se dizer que as ações desses grupos se davam, basicamente, pela lógica do medo, sem qualquer mediação, tendo a morte como resolução: são "mais próximos dos pistoleiros sertanejos do que negociantes da segurança hoje encontrados na cidade" (ZALUAR; CONCEIÇÃO, 2007, p. 91). Neste momento, a capilaridade ainda era baixa, a atuação difusa, as estratégias econômicas frágeis e desarticuladas, bem como sua inserção na política.

Ao longo da década de 1990, pioneiramente, a Baixada Fluminense elegia integrantes de grupos de extermínio para vereadores, prefeitos e deputados, ao passo que na Zona Oeste, a favela de Rio das Pedras - pioneira na atuação das milícias na cidade do Rio de Janeiro - empreendia as primeiras configurações para criação de consensos. Ou seja, a prática do medo e do código de conduta deu lugar a uma atuação mais amena, menos violenta e mais propagandeada. Exaltava-se a inexistência de tráfico de drogas, buscavam evidenciar trabalhos "sociais" para crianças e dialogavam com a população sobre as necessidades locais (BURGOS, 2002). Este processo almejava construir a confiança da população e colocar os milicianos no poder público como porta-vozes da comunidade. Paralelamente a esta atuação as receitas desses grupos diversificaram-se, apresentando uma cartilha de serviços: comércio de água, botijões de gás, materiais de construção, vendas de terrenos ilegalmente, formação de oligopólios de transporte alternativos, dentre outros.

43 A estratégia bem sucedida utilizada em Rio das Pedras tão logo se dissipou por várias áreas cariocas, sendo levadas a cabo, neste momento, fundamentalmente, por funcionários da segurança pública do Rio de Janeiro, que viam esta atividade como complemento de renda. Enquanto crescia o número de milicianos, as favelas cariocas ainda eram tomadas por facções criminosas tradicionais, como o Comando Vermelho (CV) e os Amigos dos Amigos (ADA) por exemplo, o que configurava a cidade maravilhosa como área violenta e tomada pelo crime organizado, com várias faces e enredos.

44 A problemática do crime organizado - leia-se, neste momento, tráfico de drogas ${ }^{11}$ ocupava diariamente as capas de jornais e revistas, permeada de sensacionalismo sempre em busca de um salvador/herói x vilão. Por um lado, criava-se consenso fazendo os moradores de áreas tomadas por milícias se vangloriarem por não terem a presença do tráfico de drogas em sua área; por outro, representantes das milícias se introjetavam no poder público legislativo e executivo, dando, mesmo que de longe, suporte as milícias; por último, a mídia passou a utilizar o termo milícia ao invés de grupos armados, grupos de extermínio e outras adjetivações, o que se conformava como uma "alternativa real" à violência e ao crime organizado.

A complexidade da questão da violência, alterada de forma significativa pelo surgimento das milícias/grupos de extermínio diretamente operados pelo aparato policial, é simplificada pelo embate entre o bem e o mal, midiaticamente propagado. De um lado, destemidos e corajosos defensores do Estado de direito, do outro, facínoras que submetem a população ao domínio do medo e do crime. Que controlam áreas faveladas que precisam ser libertadas pelas forças do bem e da ordem (ALVES, 2008, p. 37).

Alves (2008) explicita que estes grupos ficaram durante uma década e meia sem qualquer forma de intervenção do poder público, o que possibilitou sua expansão em termos econômicos, territoriais, políticos, bélicos e hegemônicos, firmando parcerias com outros grupos milicianos e com esferas do poder público, tudo isso à sombra 
(ROCHA; MOTTA, 2020). Isto trouxe mais uma questão para o autor: o entrelaçamento entre o que é Estado e o que é crime organizado, ou melhor, "até que ponto o próprio Estado encontra-se envolvido no crime, ou mesmo, promove e organiza o crime" (ALVES, 2008, p. 37).

De fato, as milícias só ganharam notoriedade enquanto problema a partir de 2007 com a morte de um jornalista na favela do Batan, em Realengo, na Zona Oeste do Rio de Janeiro, pelo grupo conhecido como "Águia" e, posteriormente, com a CPI das milícias em 2008, quando houve uma melhor caracterização do que era e o que são as milícias. Desde então um esforço enorme tem sido feito no intuito de desnudar as formas de atuação das milícias no território, tendo sido descoberto, por exemplo: construção de prédios para venda e sua administração, venda de saibros e areia, controle de vias, tributação sobre pescadores, transportes em geral e, inclusive, acordos estabelecidos com traficantes, ou seja, os milicianos entraram no comércio varejista de drogas: "narcomilícia".

Se antes a interdição ao comércio de drogas ilícitas era uma das principais características das milícias, hoje muitos desses grupos exploram essa vantajosa atividade comercial, assim como exploram todas as outras atividades econômicas encontradas nessas localidades. Da mesma forma, esse mesmo grupo de milicianos protagoniza a aliança com uma facção de traficantes de drogas. Juntos, iniciaram uma grande disputa armada por territórios com a maior e mais antiga facção do estado, o Comando Vermelho (ROCHA; MOTTA, 2020, p. 241).

No entanto, apesar de dados, pesquisas e grupos se debruçando para compreender e formalizar ações concretas de políticas públicas, as milícias se mostram mais fortes e articuladas do que se imaginava. As incursões militares com usos de helicópteros e carros blindados (caveirões) raramente são utilizados em áreas de domínio da milícia, mantendo-se, como sempre, em favelas dominadas pelo tráfico ${ }^{12}$. Também questiona-se até que ponto as ações de inteligência da polícia não vazam e chegam até estes grupos que são formados por agentes ou ex-agentes de segurança ${ }^{13}$. Além disso, como defendido por parlamentares algumas vezes, seria melhor lidar e firmar acordos com agentes "paralelos" do que lidar com "bandidos/traficantes" ${ }^{14}$. Ora, em termos práticos, é difícil imaginar que grupos grandes, complexos e visíveis como são as milícias possam de modo contínuo fazer "justiça" com as próprias mãos a não ser que alguém (ou alguns) com autoridade acredite que tal atuação seja útil para os interesses que defende.

O caso mais recente que tornou público e notório o poder e relação íntima com políticos importantes foi a execução de Marielle Franco e Anderson Gomes, pois, como indicam algumas investigações, existem claras conexões da milícia com o poder público ${ }^{15}$ : polícia militar e políticos.

As milícias são hoje a expressão mais contundente do neoliberalismo autoritário no Rio de Janeiro, no qual a ilegalidade e a criminalidade são condições de possibilidades para a expansão dos mercados e sobrevida do capitalismo em crise que necessita constantemente utilizar a repressão aos descontentes e expropriá-los.

\section{Considerações finais}

Com a crise da década 1970, os índices econômicos passaram a apresentar resultados cada vez mais inexpressivos e cruéis: baixo crescimento, desemprego estrutural, concentração de renda, acentuação da violência, desindustrialização, inflação, crises 
cambiais, além de muitos outros exemplos que poderiam preencher estas linhas. Nesse sentido, a partir desse momento, se tornou progressivamente difícil conciliar a gestão dos pobres/classe trabalhadora via políticas sociais com políticas para reprodução do capital, de modo que, a fina camada de gelo que sustentava o grupo mais fraco rompeu: no caso, os "indesejáveis". E, diferentemente dos países centrais que vivenciaram avanços sociais robustos, nos quais, em grande medida, se assegurou, mesmo pós-crise e pós-receituário neoliberal que imputava a diminuição do Estado, condições dignas à população; enquanto que no Brasil, o suposto Estado de bem-estar social foi frágil, distante dos moldes do Ocidente, bem como adentrou às dinâmicas financeiras e de gestão da crise de forma subordinada.

51 Pelo lado econômico a medida encontrada para assegurar a rentabilidade e a longevidade do modo de produção capitalista ocorreu pela predominância das finanças e pelo aparato político-ideológico do neoliberalismo ditando políticas de Estado (e a redução deste) e dinâmicas cotidianas. Destarte, pela dificuldade de produzir valor novo na produção real, as cidades tornam-se locais privilegiados para garantir alguma lucratividade ao capital em crise, posto as atividades propostas para benefício do capital imobiliário, financeiro e da construção civil, como as incursões de requalificação urbana, tornando-as belas, atrativas, excitantes, rentáveis, administradas como empresas. A esse respeito, pode-se realçar Barcelona, Porto, Rio de Janeiro, etc.; locais que, cada um com suas especificidades, serviram/ servem como alternativa ao capitalismo em crise.

O Rio de Janeiro, se adequando às dinâmicas exigidas pelo capital ensejou mudanças substanciais no espaço urbano no que tange áreas comerciais, áreas de lazer e turismo. Além, é claro, das medidas vinculadas ao novo urbanismo militar no qual modificou substancialmente a estrutura física, cultural, política e social das cidades. A esse respeito, Graham (2016) contribui para o entendimento do novo urbanismo militar, pois as tecnologias antes utilizadas para o monitoramento da Guerra Fria, tornaram-se instrumentos do cotidiano, utilizadas em larga medida no terceiro mundo. É exatamente nessa encruzilhado que o Rio de Janeiro se encontra: cidade neoliberal e urbanismo militar, os dois entrelaçados, vivendo juntos, dando sobrevida ao capital em crise e impedindo maiores revoltas e confinando indivíduos indesejáveis.

Portanto, a militarização do espaço urbano no Rio de Janeiro, com toda a lógica policial de confronto, retomada de áreas criminalizadas - UPPs ou não -, uso continuo e progressivo de técnicas militares do cotidiano e o domínio direto realizado por forças "paramilitares" (leia-se milícias) transformou as favelas e periferias em espaços de confinamento, onde uma parcela da população cada vez mais restrita às dinâmicas e circuitos econômicos nas áreas centrais buscam alternativas onde residem, vivendo, um duplo confinamento espacial: excluídos dos processos econômicos e controlados por forças de segurança legais e ilegais (NESIME; BOTELHO, 2020).

54 Nesse sentido, as áreas controladas por milícias podem ser vistas, cada qual a sua maneira, como territórios onde se estabelece uma dinâmica própria de atuação e controle - econômico e espacial. No entanto, apesar disso, não devem ser analisadas isoladamente, somente como um processo histórico específico, que foram se complexificando ao longo dos anos, mas sim como parte do processo do urbanismo militar e utilizada em prol deste.

Assim, no decurso do argumento apresentado pelo presente artigo, buscou-se, em primeiro lugar, somar aos diversos intentos de pesquisa que procuram entender o 
fenômeno das milícias, posto a urgência de controle da expansão desses grupos. Porém, diferentemente de estudos econômicos que buscam mensurar os impactos sobre a economia do Rio de Janeiro ou a perda de capital humano; ou de estudos sociológicos que buscam as raízes na dissidência de grupos antes articulados durante a ditadura civil-militar; ou ainda de estudos no campo jurídico ou historiográfico, tentou-se, mesmo que num espaço reduzido, atribuir e entrelaçar o fenômeno das milícias no século XXI no Rio de Janeiro como parte de uma totalidade.

Para tanto, o intuito principal foi a utilização do método dialético - singularidade, particularidade e totalidade. Ou seja, as milícias foram tratadas como uma singularidade específica do Rio de Janeiro ${ }^{16}$ e para isso promoveu-se uma discussão com alguns dos principais autores do tema, tentando extrair os elementos que auxiliassem na hipótese aventada; as cidades neoliberais como particularidade do capitalismo contemporâneo, de forma a realçar as mudanças ocorridas com o novo padrão de acumulação, no qual a cidade se tornou um dos entes fundamentais em assegurar lucro ao capital em crise; e a crise estrutural do capital como totalidade do fenômeno (lógica de reprodução ampliada do capital em crise), que auxilia a enxergar as mudanças ensejadas após a década de 1970.

57 A utilização desse caminho, apesar de trazer uma interpretação incomum, não tem o intuito de esgotar os estudos na temática e nem tampouco tensionar com os esforços realizados. Assim, esse artigo se propôs a contribuir para a análise da violência no Rio de Janeiro, focando no caso das milícias.

\section{BIBLIOGRAFIA}

ALVES, José Cláudio Souza. Milícias: mudanças na economia política do crime no Rio de Janeiro. Segurança, tráfico e milícia no Rio de Janeiro. Rio de Janeiro: Fundação Heinrich Böll, p. 33-36, 2008.

ALVES, José Cláudio Souza. Dos barões ao extermínio: Uma história de violência na Baixada Fluminense. Rio de Janeiro: Consequência, 2019 [2003].

BELLUZZO, Luiz Gonzaga. O declínio de Bretton Woods e a emergência dos mercados "globalizados". Economia e sociedade, v. 4, n. 1, p. 11-20, 1995.

BOTELHO, Maurilio Lima. Desenvolvimento, espaço e crise estrutural. Espaço e Economia [Online], 2 | 2013, postado online no dia 09 março 2013, consultado o 17 julho 2020. Disponível em: URL:http://journals.openedition.org/espacoeconomia/153. Acesso em: 27 mar. 2021.

BRENNER, Robert. La economia de la turbulencia global. México: Ediciones Era, 2013.

BURGOS, Marcelo Baumann. Favela, cidade e cidadania em Rio das Pedras. In: BURGOS, Marcelo Baumann (org.). A utopia da comunidade - Rio das Pedras, uma favela carioca. Rio de Janeiro: PUC-Rio, Loyola, 2002. 
CALDEIRA, Teresa Pires do Rio. Enclaves Fortificados: a nova segregação urbana. Novos estudos CEBRAP, n. 47, 1997.

CHASIN, José. Marx - Da Razão do Mundo ao Mundo sem Razão. In: Marx Hoje. São Paulo: Nova Escrita Ensaio, Ano V, N. 11/12, 1983.

CHASIN, José. A sucessão na crise e a crise na esquerda. In: A miséria brasileira. Santo André: Estudos e Edições Ad Hominem, 2000.

CHESNAIS, F. A finança mundializada. São Paulo: Boitempo, 2005.

DAVIS, Mike. Planeta Favela. São Paulo: Boitempo, 2006.

DE MATTOS ROCHA, Lia; DA MOTTA, Jonathan Willian Bazoni. Entre Luzes e Sombras: o Rio de Janeiro dos Megaeventos e a militarização da vida na cidade. Interseções: Revista de Estudos Interdisciplinares, v. 22, n. 2, p. 225-248, set. 2020.

GRAHAM, Stephen. Cidades Sitiadas: o novo urbanismo militar. São Paulo: Boitempo, 2016. HARVEY, David. From Managerialism to Entrepreneurialism: The Transformation in Urban Governance in Late Capitalism. Geografiska Annaler, Estocolmo, 71b, p. 3-17, 1989.

HARVEY, David.Condição pós-moderna. São Paulo: Loyola, 2002 [1989].

LEFEBVRE, Henri. Espaço e política. Belo Horizonte: UFMG, 2008.

MARICATO, Ermínia. As ideias fora do lugar e o lugar fora das ideias. In: MARICATO, Ermínia; VAINER, Carlos; ARANTES, Otília. A cidade do pensamento único: desmanchando consensos. $3^{\mathrm{a}} \mathrm{Ed}$. Petrópolis: Vozes, 2002.

MARICATO, Ermínia. É a questão urbana, estúpido! 2013. Disponível em: <http:// www.diplomatique.org.br/artigo.php?id=1465>. Acesso em: 16 Jul. 2020.

MARICATO, Ermínia. Para Entender a Crise Urbana. São Paulo: Expressão Popular, 2015.

MÉSZÁROS, István. Para além do capital. São Paulo: Boitempo, 2002.

MÉSZÁROS, István.A crise estrutural do capital. São Paulo: Boitempo, 2009.

NESIMI, Mariana dos Santos; BOTELHO, Maurilio Lima. Das favelas às prisões: transformações na segregação urbana no rio de janeiro. Revista Continentes, [S.1.], n. 16, p. 285-315, jun. 2020.

NETTO José. Paulo; BRAZ, Marcelo.Economia Política: uma introdução crítica. São Paulo: Cortez, 2008.

OLIVEIRA, Francisco de. O surgimento do antivalor: capital, força de trabalho e fundo público. Novos estudos CEBRAP, 1988, 22: 8-22.

POCHMANN, Márcio. Proteção social na periferia do capitalismo: considerações sobre o Brasil. São Paulo em Perspectiva, São Paulo, v.18, n. 2, p. 3-16, 2004.

TAVARES, Maria da Conceição; MELIN, Luiz Eduardo. Mitos globais e fatos regionais: a nova desordem internacional.

Globalização - O fato e o Mito. Rio de Janeiro: Editora Uerj, 1998, 41-54.

TONET, Ivo; LESSA, Sérgio. Proletariado e sujeito revolucionário. São Paulo: Instituto Lukács, 2012.

VAINER, Carlos. Pátria, empresa e mercadoria: notas sobre a estratégia discursiva do Planejamento Estratégico Urbano. In: ARANTES, O; VAINER, C; MARICATO, E. (Orgs). A cidade do pensamento único: desmanchando consensos. Petrópolis: Editora Vozes, 2002, p. 75-103. 
VALENTE, Júlia. O Rio de Janeiro no urbanismo militar e empresarial. Revista Continentes, [S.l.], n. 10, p. 7-26, jul. 2017.

WACQUANT, Loïc. Rumo à militarização da marginalização urbana. Discursos Sediciosos - crime, direito e sociedade. Rio de Janeiro, ano 11, n. 15/16, p. 203-220, 1ํe e $2^{\circ}$ semestres 2007.

ZALUAR, Alba; CONCEIÇÃO, I. S. Favelas sob o controle das milícias no Rio de Janeiro: que paz? São Paulo em Perspectiva, São Paulo, Fundação Seade, v. 21, n. 2, p. 89-101, jul./dez 2007. Disponível em http://www.seade.gov.br. Acesso em: 27 mar. 2021.

\section{NOTAS}

1. As milícias já vinham se desenvolvendo e ganhando repercussão antes de 2008, posto que essa repercussão que levou a CPI. No entanto, decide-se usar essa data como momento chave de posicionamento midiático e início do entendimento sobre o que são as milícias.

2. José Chasin durante um longo período foi teórico da crise estrutural do capital. Porém, em certo momento se afastou dessa perspectiva, criticando, inclusive, os autores que a seguiam acusando-os de catastrofistas. Neste trabalho seguiremos, mesmo que brevemente, o período em que o filósofo foi adepto desta teoria.

3. Tem-se o ensaio de um estado de bem-estar social somente com a constituição cidadã de 1988, na qual muitas políticas de caráter universal entram no texto.

4. “O Brasil foi o último dos países latino-americanos, já no começo da década de 1990, a entrar nesse circuito de submissão às políticas de liberalização financeira e comercial e de desregulamentação cambial com o objetivo de atrair recursos externos, a qualquer custo, inserindo-se de forma subordinada no novo quadro financeiro mundial" (TAVARES; MELIN, 1998, p. 51)

5. Durante os governos do Partido dos Trabalhadores o neoliberalismo se manteve em vigor, no entanto, com algumas nuances em relação à década de 1990. No presente momento, assistimos à junção entre neoliberalismo e autoritarismo.

6. Segundo Valente (2017), o Rio de janeiro a partir do prefeito César Maia (1993-1997, 2001-2009), se tornou porta de entrada do planejamento estratégico no Brasil, pois buscou superar o estigma de cidade desorganizada e violenta. Programas como Rio cidade e o Favela Bairro, além de várias políticas urbanas de embelezamento e requalificação dos cartões-postais nas áreas centrais e Zona Sul da Cidade.

7. Gestores, nestes escritos, tem o sentido de empresários.

8. O Rio de Janeiro, por exemplo, se apresenta como uma área de paz, mesmo com os altíssimos números de homicídios causados por armas de fogo em confrontos entre policiais e criminosos.

9. A esse respeito Valente (2007).

10. No documentário Notícias de uma Guerra particular (1999), o delegado da polícia civil Hélio Luz argumentou que a função policial era manter dois milhões de habitantes das favelas, calmos e sob controle através da repressão: "E nós fazemos um negócio bem sofisticado. Na África do Sul eles colocam arame. Aqui é sem arame". Disponível em: https://www.youtube.com/watch? v=DDFt52g29Sw. Acesso em: 01 abr. 2021.

11. Isto remete ao processo iniciado na década de 1980, quando a cocaína chega às favelas cariocas, ampliando o afluxo de dinheiro recorrente do comércio varejista direcionado aos consumidores de classe média.

12. Segundo levantamento do jornal de notícias UOL, os confrontos armados com a polícia que geraram mortos não foram identificados em áreas de milícias. Consultar: RAMALHO, Sérgio. "Polícias mataram 881 pessoas em 6 meses no RJ, nenhuma em área de milícia". Disponível em: 
https://noticias.uol.com.br/cotidiano/ultimas-noticias/2019/08/20/policias-mataram-881pessoas-em-6-meses-no-rj-nenhuma-em-area-de-milicia.htm. Acesso em: 27 mar. 2021.

13. Por exemplo, na Zona Oeste, $030^{\circ}$ Batalhão de Polícia Militar realiza incursões em áreas comandadas por traficantes e há relatos de moradores que policiais desse batalhão atuam legalmente como policiais e ilegalmente como milicianos (ROCHA; MOTTA, 2020). RJ investiga policiais suspeitos de atuar como agentes duplos para as milícias. 27 de fevereiro de 2019. Disponível em: https://noticias.uol.com.br/cotidiano/ultimas-noticias/2019/02/27/rj-investigapoliciais-suspeitos-de-atuar-como-agentes-duplos-para-milicias.htm. Acesso em: 07 abr. 2021.

14. "Tem gente que é favorável à milícia, que é a maneira que eles têm de se ver livres da violência. Naquela região onde a milícia é paga, não tem violência”. Trecho proferido pelo então, na época, deputado federal Jair Bolsonaro. Em discursos Bolsonaro já exaltou milícias e grupos de extermínio. Disponível em: <https://blogs.oglobo.globo.com/bernardo-mello-franco/post/emdiscursos-bolsonaro-ja-exaltou-milicias-e-grupos-de-exterminio.htm>l. Acesso em: 29 abr. 2021.

15. Caso Marielle: testemunha envolve vereador e miliciano em assassinato, informa 0 Globo. Disponível em: https://g1.globo.com/rj/rio-de-janeiro/noticia/caso-marielle-testemunhaenvolve-vereador-e-miliciano-em-assassinato-informa-o-globo.ghtml. Acesso em: $30 \mathrm{abr} .2021$.

Marielle, Bolsonaro e a milícia: os fatos que escancaram o submundo do presidente. Disponível em: https://www.brasildefato.com.br/2020/03/14/marielle-bolsonaro-e-a-milicia-os-fatos-queescancaram-o-submundo-do-presidente. Acesso em: 30 abr. 2021.

16. Mesmo presente em outros países e outros estados brasileiros, a milícia do Rio de Janeiro possui características próprias e bem marcantes nos estudos sobre violência, de modo que nos reservamos o direito de tratá-la como um fenômeno singular.

\section{RESUMOS}

A violência e, mais especificamente, a atuação, expansão e complexificação das milícias assumiram proporções agudas no estado do Rio de Janeiro. As milícias, que durante décadas se desenvolveram por baixo dos panos, se tornaram simultaneamente o principal assunto e problema da segurança pública carioca hoje. Destarte, duas perguntas geralmente são feitas: qual o motivo de seu crescimento e como se desenvolveram sem que houvesse publicização e atuação por parte do poder público? Apesar das várias explicações consagradas e esforços no sentido de caracterização desses grupos, o objetivo do presente artigo é trazer uma análise pouco difundida nos estudos sobre as milícias, qual seja, a compreensão a partir da conexão entre o urbanismo militar ou urbanismo miliciano no Rio de Janeiro com as cidades neoliberais/globais e a crise estrutural do capital que se manifesta desde a década de 1970.

The violence and, more specificaly, the performance, expansion and complexification of militias took on acute proportions in the state of Rio de Janeiro. The militias, which for decades developed under cover, have become the main issue and problem of public security in Rio at the present time. Thus, two questions are usually asked: what was the reason for its growth and how did it develop without publicizing and acting by the public authorities. Despite the various acclaimed explanation and efforts to characterize these groups, the objective of this article is to bring an analysis that is not widespread in the studies on militias, that is, the understanding based on the connection between military urbanism or militia urbanism in Rio de Janeiro, with 
neoliberal/global cities and the structural crisis of the capital that has manifested itself since the 1970s.

La violence, l'expansion, la complexité et la façon d'agir des milices ont pris des proportions aiguës par tout l'état de Rio de Janeiro. Si d'autrefois les milices se sont développées en cachette, maintenant elles sont devenues le problème principal de la securité publique carioca aujourd'hui. Ainsi, on se pose deux questions : quelle est le motif de son agrandissement et comment ça est arrivé sans la réaction du pouvoir publique? Nonobstant les plusieurs explications et caractérisations de ces milices, on veut exploiter un chemin peu connu dans les études sur les milices: les connexions entre l'urbanisme militaire ou l'urbanisme milicien à Rio et les ville néolibérales globales avec la crise structurelle du capital depuis les années 1970.

La violencia y, más especificamente, el desempeño, expansión y complexificación de las milicias adquirieron proporciones agudas en el estado de Rio de Janeiro. Las milicias, que durante décadas se desarrollaron abajo de las telas, se han convertido en el principal tema y problema de la seguridad pública de Rio en la actualidad. Así, se suelen plantear dos preguntas: cuál fue el motivo de su crescimiento y cómo se desarrolló sin dar a conocer y actuar por parte de las autoridades públicas. A pesar de las diversas explicaciones consagradas y los esfurzos por caracterizar a estos grupos, el objetivo de este artículo es basado em la conexión entre urbanismo militar o miliciano en Rio de Janeiro, con las ciudades neoliberales/globales y la crisis estructural del capital que se manifiesta desde la década de 1970.

\section{ÍNDICE}

Mots-clés: crise structurelle; crise urbaine; militarisation; urbanisme militaire ; Rio de Janeiro

Keywords: structural crisis; urban crisis; militarization; military urbanism; Rio de Janeiro Palabras claves: crisis estructural; crisis urbana; militarización; urbanismo militar; Rio de Janeiro

Palavras-chave: crise estrutural; crise urbana; militarização; urbanismo militar; Rio de Janeiro.

\section{AUTOR}

\section{UTANAAN REIS BARBOSA FILHO}

Graduado em Ciências Econômicas pela Universidade Federal Rural do Rio de Janeiro (UFRRJ) e Mestrando em Planejamento Urbano e Regional pelo Instituto de Pesquisa e Planejamento Urbano e Regional da Universidade Federal do Rio de Janeiro (IPPUR/UFRJ). Pesquisador do Coletivo Marxista da Rural (MAR-UFRRJ) e do Observatório Baixada Cultural (ObaC). 